\title{
Analysis of Pragmatic Functions of English Euphemism from the Perspective of Pragmatic Principles
}

\author{
Yujuan Cao \\ Shanxi Normal University, Shanxi, China
}

\begin{abstract}
Euphemism is a common linguistic phenomenon in human society and plays an important role in human daily communicative activities. In the process of the development of euphemism, there are many studies on euphemism. On the one hand, it has achieved rich achievements, and on the other hand, there are also deficiencies. This article will discuss the pragmatic functions of English euphemism under the guidance of pragmatic principles. By observing and studying the applied examples of euphemism in life, at the same time to link the guidance of pragmatic principles, the paper concludes that the euphemism plays different functions in people's lives, and enables both parties to successfully complete communication.
\end{abstract}

Index Terms - euphemism, cooperation principle, politeness principle, pragmatic functions

\section{INTRODUCTION}

\section{A. Background}

Euphemism has been highly concerned by the linguistic community and has always been a research hotspot. The research results are very abundant. Up to now, researches on euphemism have mainly focused on such domains as semantics, pragmatics, rhetoric, sociolinguistics, and fuzzy linguistics. What's more, findings in these areas provided people with a correct understanding of euphemism, and there is a great significance on the study of euphemism.

Though there are many researches on euphemism at home and abroad, and great achievements have been made, there are also problems in the researches made before. First of all, the phenomenon of simple repetition is more serious; secondly, many articles remain in the shallow introductive level and do not do in-depth and meticulous researches; thirdly, there are few monographs about euphemistic researches at home and abroad. Based on the problems in the euphemism researches, it is necessary to carry out a more in-depth study of this linguistic phenomenon, which has caused widespread concern. Hence, scholars should better study euphemism based on previous theories and make up for the shortcomings of euphemistic researches.

\section{B. Purpose and Significance}

Euphemism uses a more subtle tone to express all kinds of intense and unspeakable discourses and uses rich linguistic expressions to achieve unique rhetorical meanings and produces unique linguistic effects. Moreover, under the usage of pragmatic principles, the pragmatic functions produced by euphemism can make conversations more polite, and can avoid unnecessary embarrassing situations and enable both parties to complete their communications successfully. Hence, the purpose of this article is to find out the functions of euphemism under the guidance of pragmatic principles and to help readers better understand the applications of euphemism in life.

Euphemism has a wide range of applications in various fields. Many scholars have expressed their opinions on the functions and applications of euphemism, and scholars also have conducted in-depth researches on euphemism and have put forward their own opinions on the functions of euphemism. This article will further analyze functions of euphemism and put forward my own opinion based on the previous theories in order to let people feel the existence of euphemism in daily life.

\section{LITERATURE REVIEW}

A proposed theory has a guiding role in practice. The correct theories can better guide the euphemism to function and to better serve people's lives. The simple introduction of the theoretical basis for the study will be showed as follows:

\section{A. Pragmatic Principles}

To ensure smooth communication, language users must abide by some basic principles, which are called the pragmatic principles, including the principle of cooperation put forward by American philosopher Grice in 1967 and the principle of politeness raised by Leech.

1. The Cooperation Principle

When you talk with other people, you should make your speaking as is required. In actual communication, the 
speaker usually means a lot more than what he is said. H.P. Grice thinks that the production of speaking must be governed by some rules. This is what he calls the Cooperation Principle, which has four maxims: the maxim of quality, quantity, relation and manner.

Simply speaking, the Cooperation Principle guides a person that they should say something that is true in a clear and relevant manner. On the one hand, the above four maxims are extremely important in dialogue interactions, because these conversational maxims are necessary to ensure the participants to effectively and rationally use language in the conversation on the basis of cooperation. On the other hand, language users in communication may violate or despise these conversational maxims to achieve their communicative goals.

2. The Politeness Principle

The principle of cooperation explains the relationship between the literal meaning and the actual meaning of discourse, but it does not explain why people often violate the principle of cooperation and express their thoughts in an implicit and indirect way to communicate. Hence, Leech proposed the principle of politeness to remedy this deficiency of the principle of cooperation.

Leech puts forward six maxims of the Politeness Principle which runs as follows: Minimize the expression of impolite beliefs and maximize the expression of polite beliefs. The politeness principle contains six parts: the tact maxim; generosity maxim; approbation maxim; modesty maxim; agreement maxim and sympathy maxim.

\section{B. Researches on Euphemism}

Euphemism plays an increasingly important role in people's lives. On the one hand, it not only makes people's conversations smoother, but also enhances people's intimacy; on the other hand, people also pay more and more attention to the study of euphemism. So there have been many researches on euphemism at home and abroad, and people have come to understand and experience euphemism from different perspectives.

1. Researches Abroad

Many scholars have conducted in-depth researches on euphemism and have put forward their own opinions on the functions of euphemism. Western scholars studied euphemism long time ago.

The Puritans of the 17th century pursued zealously in language and grace. Noah Webste revised the Bible in 1833, making it a clearer version of vulgar words and marking euphemism as the ultimate expression.

In 1880s, the first man who used the term euphemism for the first time in English was the English writer Gorge Blunt. He gave such a definition: Euphemism is a good of favorable interpretation of a bad word.

Many scholars (Mencken, Bollinger, Neman and Sliver) have conducted researches on euphemism one after another. H. L. Mencken explored in great detail how euphemism came into being and became popular in The American Language and he proposed that euphemism plays important role in human life. (Mencken, 1936)

James George Frazer, a British scholar, was one of the earliest scholars to start systematic research on euphemism. In A golden Bough - A Study in Magic and Religion, Frazer used a great deal of space (four chapters) to study taboo words, behaviors, things and names.

Leech, G. N. introduced the principles of pragmatics in Principle of Pragmatics, he said that pragmatic principles can be divided into two classes: the cooperation principle and the politeness principle. (Leech, 1983)

In 1985, D. J. Enright published a collection of essays entitled Fair of Speech, the Use of Euphemism, which collected many essays on euphemism and provided information for euphemistic researches in the future.

In 1991, Allan Kate Burridge published Euphemism and Dysphemism, a book that is very useful for scholars who study English euphemism from a pragmatic point of view. Burridge proposed that euphemism is the substitution of an agreeable or inoffensive word or term for one that is indelicate, blasphemous, or taboo. Various types of euphemisms are found in the Bible. (Burbidge, 1991)

In 2003, Wierzebecka, A. published Cross-Cultural Pragmatics: The Semantics of Human Interaction introduced the principles which used in human interactions. He proposed that pragmatic can be used as a guidance of human interactions (Wierzebecka, 2003)

Hugh Rawson, an American scholar, once said that euphemism is so deeply embedded in our language that no one of us can spend a day without euphemism, even those who claim to be straightforward, and he proposed that euphemism embodies the British and American linguists' research on euphemism for many years. (Hugh, 1981)

2. Researches at Home

Similar to Western countries, the development of euphemism in China is also influenced by factors, such as traditional concepts and religious ideology. Language and culture are also inextricably linked. As a famous ancient civilization and state of ceremonies, China has always attached great importance to social and family harmony. Under such a historical and cultural background, Chinese euphemism has made great progress.

In 2000, according to the theory of Grice and Leech, Shu Ding Fang introduced the relationship between the pragmatics principles of the verbal communication process of euphemism and he also said that the problems of euphemism can be solved under the guidance of pragmatic rules. This has a profound influence on the study of euphemism. (Shu, 2000)

Hongrui Wen divided motives for motivating euphemism into fear and politeness. He believed that the desire to love face or fear of losing face is widespread and transcends all cultural boundaries, no matter what ethnic group he is or what kind of person he is. When grown up in a cultural context, people always pay attention to face. (Wen, 1996) 
Changhuai Lu proposed that the pragmatic functions of euphemism are avoiding taboos and avoiding vulgarity in Introduction to Linguistics. (Lu, 2004)

Runqing Liu put forward euphemism and taboo in the New Linguistics Tutorial, pointing out that the use of euphemism has greatly changed people's communicative methods and improved people's communicative activities. (Liu, 2006)

Zhuanglin $\mathrm{Hu}$ introduced euphemisms and taboos in The Linguistics Course to highlight the role of euphemisms in life. He said that euphemisms are useful in daily communication. (Hu, 2011)

\section{The NeCessity of Studying EuPhemism Under PRAgMatic PrinCIPLES}

\section{A. The Guiding Role of Pragmatic Principles}

The pragmatic principles refer to the cooperation principle and the politeness principle. In actual communication, people use pragmatic principles to guide their daily life. Euphemism is a common phenomenon in the history of human beings, and it has been euphemistically expressed in different linguistic societies and at different social levels for some time and has drawn people's attention and focus. In real life, people use euphemistic, elegant, polite words instead of renegade, hurting, vulgar words to make each other feel comfortable and unharmed.

Through observation, it is not difficult to find that euphemism is used in people's daily communication, while the pragmatic principles are used to guide people's communication activities, so the pragmatic principles play a certain guiding role in the use of euphemism.

For example, the tact maxim of the politeness principle: Minimize the damage to others and benefit the most. For example, would it possible for you to lend me your watch? That is to say, when you talk to people, you should be strategic. Minimize the damage to others and benefit the most. When you want to lend a watch, you say "would you..." in this way will make people comfortable and feel that you are a polite man, and maybe promise your requirement. Using this expression makes the sentence more euphemistic. That is to say, under the guidance of the tact maxim, people express their ideas more euphemistically. In conclusion, pragmatic principles are the guidance for using euphemism.

Take approbation maxim of the politeness principle for another example: Try to reduce the derogation of others, and try to exaggerate the praise of others. For example, "you are really a good teacher!" To see more of the strengths of others in the conversations and to praise others for more praise will make people happy and make the conversation smoother. The approbation maxim guides people to express praises to others, so in our daily life, we try to exaggerate the praise of others. In conclusion, pragmatic principles are the guidance for using euphemism.

Another example, when communicating with others, people try to reduce dislike towards others, and express sympathy for other people's bad situations and let others feel your concern so that they can continue to share with you and promote the smooth progress of the conversation, which is called Sympathy Maxim: Do your best to reduce your distaste for others and try to exaggerate your sympathy for others. For example, A: "My grandmother died yesterday." B: "I'm sorry to hear that". Under the guidance of the sympathy maxim, people try to exaggerate sympathy for others. In conclusion, pragmatic principles are the guidance for using euphemism.

In a word, under the guidance of the pragmatic principles, people increasingly like to use euphemism to express their ideas, and in real life people use euphemism more often and more smoothly. Hence, the pragmatic principles play the guiding role for using euphemism.

\section{B. The Stimulating Effect of Euphemism on Pragmatic Principles}

In actual communication, it is inevitable for us to use the euphemism to communicate, and the usage of euphemism reflects and promotes the pragmatic principles.

For example, a parent said: someone's eaten the icing off the cake. In this sentence, the parents did not directly blame the children, but used an indefinite pronoun someone, saying only that "someone" had eaten the powdered sugar on the cake, thus violating the maxim of the manner. The purpose is to maintain the child's politeness. In actual communication, the speaker should not use marked expressions for no reason. If the speaker uses these expressions, his meaning is different from what he could have expressed with an unmarked expression. Hence, in this way people use a new way to express euphemism, and stimulate pragmatic principles to develop new expressions on maxims.

Another example, at a party, A says "Mrs. X is so fat." There is a moment of appalled silence, and then B says "The weather is sunny today, isn't it?" B has apparently refused to make what he says relevant to A's preceding remark. He thereby implicates that A's remark should not be discussed and, perhaps more specifically, that A has made something wrong. We can see that B's answer is irrelevant to A's question, but we can understand the intended meaning of B; he wants to immediately change the different topics to avoid embarrassing Ms. X. Hence, in this example, the usage of euphemism violates the maxim of relation, and the usage of euphemism reflects the cooperation principle in pragmatic principles.

In real life, in order to communicate more politely and achieve the communicative goal better, the violation of the principle of cooperation is inevitable. Use some of the makeup language, or the language has nothing to do with the topic to express their meaning more tactfully, and the purpose is to preserve the speaker's face, to make the communication be successful. Moreover, in this way, people are increasingly seeing the benefits of using euphemism, 
and using euphemism to promote the development of euphemism while promoting the development of pragmatic principles.

In conclusion, from what have been discussed above, through the examples we can find that on the one hand, the pragmatic principles guide the using of euphemism, and on the other hand, better develop pragmatic principles in the usage of euphemism, which is called the stimulating effect of euphemism.

\section{Pragmatic Functions of Euphemism under Pragmatic Principles}

With the development of the times, people are paying more and more attention to the skills of speaking and the way they express their ideas. Not only must they be polite, they should also pursue euphemistically effective results. As a result, euphemism has received more and more attention from people, and the use of euphemism is also seen everywhere in people's lives. For example, for the word "death", in order to avoid directly mentioning this unpleasant expression, people would use euphemism: “go”（走了）, “die”（去世）, “go west”（归西天）, “have a good ending” (功德圆满了) , “be with God” (和上帝一起了), etc.

The role of euphemism in the context of real life is called the pragmatic function of euphemism. Pragmatic functions of euphemism play a great role in people's lives. The use of euphemism can avoid the use of words that people do not like to hear and change into more acceptable expressions, which can make the two sides' conversation more respectful and polite; it can also hide the original appearance of the matter and reduce people's sense of disgust; it can also resolve the embarrassing situation and stimulate the atmosphere of conversation.

Generally speaking, under the principles of pragmatic the euphemism has avoidance function; politeness function; elegance function; disguise function and humor function. The simple introduction of the pragmatic functions is as follows:

\section{A. Avoidance Function}

The so-called avoidance function refers to the use of euphemism in people's conversations to avoid certain expressions. This function complies with the Sympathy Maxim under the politeness principle: Do your best to reduce your distaste for others and try to exaggerate your sympathy for others. For example, some people express embarrassing or unlucky expressions. People often use euphemism to decrease their original intentions and use a kind of expression that people are more willing to accept. When it comes to death, people are more inclined to express "death" as "die" (去 世); “long-dead life” (与世长辞); “rest” (安息); “long sleep” (长眠), etc. In English also have some expressions, such as "be with God"; "to fall asleep"; "to go to a better place"; "no longer with us", etc.

Take some sentences in "Dream of the Red Chamber" as an example to analyze the euphemism's avoidance function. For example: Suddenly I saw a few people in Eastern Mansion, they ran in panic and said, "The old man has had a good day!" Everyone was shocked, and hurriedly said, "He was not even ill, how could he pass away so suddenly!" The family said: "Master exercises every day is sure to be a success. The immortal goes." In these sentences, the reader uses "had a good day"; "pass away" and "immortal" rather than "die" in order to avoid unhappy expression.

Another example, contraception, which is a necessary measure for family planning, was originally bright and straightforward, but today people are reluctant to say such words. Family planning is the term we use, while in western country, it is called birth control. Birth control is actually a euphemism for family planning. On the surface, it seems to be an economic planning or an education program, and it literally does not involve children's affairs. In fact, it is talking about this aspect.

Hence, the phenomenon such as live, death, sickness, sexuality, raping, and catastrophes, if spoken directly, it would give people a dirty, harsh feeling. Conversely, if expressed in an indirect and implicit manner, you can avoid taboos and give people a comfortable feeling.

\section{B. Politeness Function}

The politeness function of euphemism refers to people's consideration of each other's face in communication, and the usage of a more euphemistic expression will not cause the other person to fall into an awkward situation and make the conversation go smoothly. This function complies with the politeness principle. Leech puts forward the Politeness Principle which runs as follows: Minimize other things being equal the expression of impolite beliefs and maximize the expression of polite beliefs.

For example, some words involving physical defects or appearance defects generally cause people who are with such defects to be frustrated or disgusted, and even cause inferiority. Therefore, in communication, such words are generally not easy to use, and euphemisms are used instead when necessary or when they have to be expressed. For example, use the euphemistic expression "mentally deranged" to instead of "mad"; use "slow-witted", "unwise" to instead of "foolish"; use "unable to hear" rather than "deaf"; use "plain-looking" rather than "ugly"; and use "well-developed", "full-figured" rather than "fat". This function complies with Tact Maxim: Minimize the damage to others and benefit the most. That is to say, when you talk to people, you should be strategic. Minimize the damage to others and benefit the most.

Take some sentences in "Dream of the Red Chamber" as an example to analyze the euphemism's politeness function. For example, Chai Chen thanked him endlessly and said: "After serving, bring my worthless son to the house and give 
thanks." In this sentence, the author uses worthless son to refer to his son, which is a polite expression.

"In the past, I went astray in this way myself and suspect your honorable son may do the same. If it is difficult for him to work hard at home, he is very welcome to my humble house..." In this sentence, the author uses humble house to refer to his house, which is a polite expression.

The politeness function of euphemism, under the guidance of politeness principle can make people's communication more polite, more decent and more helpful.

\section{Elegance Function}

Generally speaking, the elegance function of euphemism refers to the politeness problem in communication, and usually achieves the effect of politeness by virtue of the ambiguity generated by deviations from the meaning of words, so that the communicative parties avoid irritation and eliminate vulgarity in verbal communication, and make people feel elegant. But some words are actually often used as curses or discourses by people when they are angry, depressed and unsatisfied, or they have evolved into verbal expressions of rude people. In desperation, saying dirty words is an unavoidable thing in most people's life. Therefore, those dirty words or unlucky words, and words that sound harsh and disgusting have corresponding euphemism, in order to make the expression as elegant as possible. The examples will be introduced as follows:

For example, a common curse term, the euphemism of “hell” (见鬼去!) is “ oh, heck!”. Another example, “bloidy” is "blinking", "You blinking fool!" Such expressions, as long as they are not deliberately aimed at someone, generally do not cause anger or resentment from others. This function complies with Tact Maxim in politeness principle, minimize the damage to others.

There are also many other annoying terms, so in conversations people often choosing to avoid them. For example: people are more likely to use the euphemism form "drop the kids off at the pool" instead of the "shit"; use "break wind" instead of "fart"; and use "go to the bathroom" instead of "piss", though some physiological nouns are not very elegant. For example, shit, it is very vulgar to say, people in the daily change to stool, solution, go to the toilet.

For example, Lu Xun wrote: The professor said: "But his article, I have read it and put it where it should go." The euphemism that the professor used the place to go refers to the places where people do not want to mention ---toilets. The upper-class people think that the word "toilet" is dirty and disdainful. When one speaks the world, he becomes rough. Even though elegant people, they have to go to the place where they don't want to call their names. In order to express the toilet elegantly, people often use euphemism to express, such as “lavatory”(则所), “latrine”（公共则所）, “dressing room”（更衣室）, “powder room”（化妆师）, “lounge”（休息室）and so on.

The elegance function of euphemism, under the guidance of politeness principle can make the expression as elegant as possible, and can make people feel more comfortable.

\section{Disguise Function}

The basic feature of the euphemism's disguise function is the inconsistency between the surface meaning and the unsaid actual meaning. These inconsistencies can manifest itself between the word and the signified; between appearance and truth; between the language's communicative function and the disguised essence. The reason why people use euphemism in communication is that the euphemism has a vague color and is quite deceptive, and it has become a tool for deceiving politicians and profiteers. Sometimes it may make people feel confused that euphemism is used as a way to express something directly. The examples will be introduced as follows:

For example, the governments or businessmen always use it to disguise the reality, and it means that they use good words to mask things which are not beautiful in reality. Hence, this function violates the Maxim of Quality of the cooperation principle: Try to make your contribution one that is true. That is to say what you said is that you think it is true; do not say what you think it is not true. The governments or businessmen violate the maxim of quality to disguise the reality.

Another example, in the Iraq war, the United States created a lot of euphemisms to "make up" the war so as not to arouse people's dislike of the war. For example, “preemptive action”（先发制人的行动） rather than “invasion”（入 侵), “pacify the area” (绥靖地区) instead of “attack”（进攻), “bombing and blasting”(轰炸扫射) called “softening up the resistance”（削弱抵抗）. Its euphemistic words were used to hide the cruelty of its war and weaken people’s dislike of war.

By means of euphemism, people can easily escape from embarrassing occasions. For example, in western community, "the poor" is called as "the needy", later it was changed as "the culturally deprived", then to "the underprivileged", at last to "the disadvantaged". So, in this case, people may feel confused that there are no poor people in that country at all. This is the disguise effect produced by the meaning of words by employing euphemism.

\section{E. Humor Function}

In daily life, it is inevitable that there will be difficult or embarrassing situations. At this moment, humor is the best regulator. You can use some witty techniques to free yourself from your awkward situation and create a harmonious and beautiful atmosphere in order to establish friendly relations with others. Therefore, in some embarrassing circumstances, euphemistic expressions can be used to help people out of trouble. This is the humor function of euphemism. 
For example, at a banquet, a famous painter wanted to return to his hometown and his students were holding a banquet. A singer also came to the party. At the beginning of the banquet, the painter went to the singer and said: "Sir, you are a gentleman. I am a villain. I will honor you first." All the people were stunned. The singer could not understand what he was doing. He asked with a smile: "What did you say?" The painter said with a smile: "You are a gentleman. You work with your mouth, while I am a villain, working with my hands." Laughed, the banquet atmosphere was very warm. Using humorous conversations in euphemisms will help people get out of awkward situations and give people a relaxed atmosphere, and make your communicative activities smooth and unobstructed.

Another example, once, Lincoln faced the audience and spoke incessantly. Suddenly someone in the crowd handed him a note. Lincoln took the note and opened it without thinking. Unexpectedly, the note was written "stupid people". At that time, the people next to Lincoln had already seen these two words. They all stared at President Lincoln to see how he handled such brazen provocations. Under the gaze of many people, Lincoln smiled a little and said: "I have received many anonymous letters. All of them are only texts, but I don't see signatures. Today, the opposite is true. There is only a signature on this note, but it lacks the text!" Voices just fell, and applause broke out on the entire venue. Everyone applauded the wisdom and humor of Lincoln. The signed man bowed his head and mixed into the crowd and slipped away. The atmosphere of the entire venue was changed from tense to relax. The speech continued.

In conclusion, humor is a kind of power in the social situation. In daily communication, the function of humor is a combination of wisdom and knowledge and can help people escape from dangerous and embarrassing situations.

The use of English euphemism functions is not only reflected in everyday life, political life and war rhetoric, but also reflected in other aspects of social life. Knowing this knowledge will help understand the complex links between language and society and at the same time, mastering English euphemism knowledge and skillfully using its functions can not only avoid short circuits in communication, but also avoid communication pitfalls and promote smooth communication activities. Under the guidance of cooperation principle and politeness principle, the pragmatic functions of euphemism play a great role in people's lives, greatly improving people's communication methods, making communication participants more polite, more refined, and more humorous to express their own ideas.

After the above discussion, we have analyzed the five functions of euphemism in life, in literary works, and in political language. Under the guidance of pragmatic principles, euphemism has greatly facilitated people's lives.

\section{CONCLUSION}

\section{A. Major Findings}

Based on the pragmatic principles, this article attempts to study the pragmatic functions of euphemism through the applications of euphemism under the pragmatic principles. This article introduced the pragmatic functions, including the avoidance function; politeness function; elegance function; disguise and humor function. Through many examples, people can easily find that euphemism plays an important role in our lives and uses a more subtle tone to express all kinds of intense and unspeakable discourses; people can also find that euphemism uses rich linguistic expressions to achieve unique rhetorical meanings and produces unique linguistic effects to make people look like polite.

\section{B. Limitations and Suggestions}

This paper is only based on pragmatic principles, there are still many deficiencies in the exploratory study of the functions of euphemism, which are left to be further criticized and corrected by scholars. The inadequacy of this article is that there are many references in the theoretical parts, and there are no good practical parts. The whole article is based on a number of proven theories and there are not many innovations. Many deficiencies also invite you to bearing with me. Thank you.

In the future there will be more and more scholars studying euphemism. People can add more case studies based on previous theories and find more functions about euphemism, and do more practices. Last but not the least, with the continuous development of society, the better combination of theory and practice makes the theory more persuasive and the articles more real.

\section{REFERENCES}

[1] Allan Kate Burbidge. (1991). Euphemism and Dysphemism. USA: Oxford University Press.

[2] Changhuai Lu. (2004). An Introduction to Linguistics. Jilin: Jilin People's Publishing House.

[3] Dingfang Shu. (2000). An Introduction to Contemporary Linguistic Semantics. Shanghai: Shanghai Foreign Language Education Press.

[4] Henry L. Mencken. (1936). The American Language. New York: Cosimo Classics.

[5] Hongrui Wen. (1996). A Survey Linguistics Abroad. Shandong: Shandong Education Publishing House.

[6] Leech, G. N. (1983). Principle of Pragmatics. London: Longman Publishing Group.

[7] Rawson Hugh. (1981). A Dictionary of Euphemisms and Other Doubletalk. New York: Crown Publisher.

[8] Runqing Liu. (2006). Linguistics: A New Coursebook. Beijing: Foreign Language Teaching and Research Press.

[9] Wierzbicka, A. (2003). Cross-Cultural Pragmatics: The Semantics of Human Interaction. Berlin: Walter De Gruyter Inc.

[10] Zhuanglin Hu. (2011). Linguistics: A Course Book. Beijing: Peking University Press. 
Yujuan Cao was born in Shanxi, China in 1995. She is currently a graduate student of the School of Foreign Language, Shanxi Normal University, Shanxi, China. Her research interests include sociolinguistics and eco-linguistics. 